\title{
Caracterização geotécnica dos solos de subleito ferroviário: investigações de campo e laboratoriais
}

O avanço dos sistemas de transportes impulsionou o desenvolvimento de novos estudos para análise do desempenho do pavimento em resposta a diferentes tipos de solicitações. Associada ao crescimento do setor, à necessidade de duplicação de vias e ao aumento de carregamento das linhas em operação, a investigação do subleito é considerada um elemento fundamental para a garantia da qualidade do desempenho do pavimento e para a operação segura e confortável dos veículos ferroviários. Este artigo teve como objetivo principal a avaliação da capacidade de suporte de um trecho da duplicação da Estrada de Ferro Carajás a partir de sondagens geotécnicas em campo e laboratoriais. O plano de investigação constou com uma análise tátil-visual dos solos para a definição do trecho do estudo, seguido da execução do ensaio de Cone de Penetração Dinâmica no pavimento da seção experimental. As amostras do subleito foram coletadas nos pontos km $216,143, \mathrm{~km} \mathrm{216,180} \mathrm{e} \mathrm{km} \mathrm{216,216} \mathrm{ao} \mathrm{longo} \mathrm{do} \mathrm{trecho} \mathrm{do} \mathrm{Pátio} \mathrm{14,} \mathrm{e} \mathrm{submetidas} \mathrm{aos} \mathrm{ensaios} \mathrm{laboratoriais} \mathrm{de} \mathrm{análise} \mathrm{granulométrica} \mathrm{completa,} \mathrm{limites} \mathrm{de}$ consistência, Índice de Suporte California (ISC ou CBR) e classificação pela metodologia MCT. Os solos foram classificados pelos sistemas SUCS e TRB como argila de baixa plasticidade e solos A-2-4 e A-4, respectivamente, com não observância do comportamento laterítico. O valor apresentado pelo ensaio de CBR indicou que o solo possui baixa capacidade de suporte, e seu uso como camada de subleito seria inviabilizada pelos padrões normativos convencionais. Neste sentido, estudos voltados à avaliação da capacidade das vias adaptadas às condições brasileiras para utilização de materiais locais são importantes fatores para redução do impacto das obras de infraestrutura ao meio ambiente, através da redução da movimentação dos terraplenos na implantação da plataforma e de remanejamentos.

Palavras-chave: Impacto Ambiental; Investigação Geotécnica; Solos Tropicais; Pavimento Ferroviário.

\section{Geotechnical characterization of railway subgrade soils: field and laboratory investigations}

\begin{abstract}
The advance of transportation systems has promoted the development of new studies to analyze pavement performance in response to different types of solicitations. Associated to the growth in the sector, the requirement for duplication of roads and the increase in loading of operating lines, the subgrade investigation is considered a key element in ensuring pavement performance quality and in the safe and comfortable operation of rail vehicles. The main objective of this paper was to evaluate the bearing capacity of a section of The Carajás Railroad duplication based on field and laboratory geotechnical surveys. The investigation plan consisted on a tactile-visual analysis of the soils to define the study segment, followed by the Dynamic Cone Penetration Test on the experimental section pavement. The subgrade samples were collected at $\mathrm{km} \mathrm{216.143,} \mathrm{km} 216.180$ and $\mathrm{km} 216.216$ along Patio 14, and subjected to particle size analysis, consistency limits tests, California Bearing Ratio (CBR) and classification according to MCT methodology. The soils were classified according to the SUCS and TRB systems as clay with low plasticity and soils A-2-4 and A-4, respectively, with no observance of lateritic behavior. The value presented by the CBR test indicated that the soil has low bearing capacity and its use as a subgrade layer would be unfeasible by conventional normative standards. In this sense, studies aimed at assessing the capacity of roads adapted to Brazilian conditions for the use of local materials are important factors for reducing the environmental impacts of infrastructure works, by reducing the movement of embankments in the platform implementation and relocation.
\end{abstract}

Keywords: Environmental Impact; Geotechnical Investigation; Tropical Soils; Railway Pavement.

Topic: Engenharia Geotécnica

Reviewed anonymously in the process of blind peer.
Received: 02/10/2019

Approved: 26/11/2019

Priscila Celebrini de Oliveira Campos (ic Instituto Militar de Engenharia, Brasil http://lattes.cnpq.br/3912686193914606 http://orcid.org/0000-0002-0612-8625 priscilacelebrini@live.com

Ben-Hur de Albuquerque e Silva (iD) Instituto Militar de Engenharia, Brasil http://lattes.cnpq.br/6509325029666357 http://orcid.org/0000-0001-6933-498X benhur@ime.eb.br

Maria Esther Soares Marques (iD) Instituto Militar de Engenharia, Brasil http://lattes.cnpq.br/8911936841113704 http://orcid.org/0000-0001-8936-2777 esther@ime.eb.br

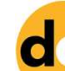

DOI: 10.6008/CBPC2179-6858.2019.006.0016
Referencing this:

CAMPOS, P. C. O.; SILVA, B. A.; MARQUES, M. E. S.. Caracterização geotécnica dos solos de subleito ferroviário: investigações de campo e laboratoriais. Revista Ibero Americana de Ciências Ambientais, v.10, n.6, p.178-193, 2019. DOI: http://doi.org/10.6008/CBPC21796858.2019.006.0016 


\section{INTRODUÇÃO}

Entre os sistemas de transportes existentes, o ferroviário destaca-se por sua natureza de transportar cargas pesadas de maneira segura, eficiente e com menor impacto ao meio ambiente quando comparado ao modo rodoviário. Segundo a ANTT (2019), no período entre 2006 e 2018, p transporte ferroviário de cargas registrou um crescimento aproximado de $38 \%$ em toneladas úteis (TU) transportadas. Dentre os subgrupos de mercadorias transportadas em 2018, destaca-se o transporte de carga de 441.376 TU de minério de ferro, o que corresponde a $77 \%$ de toda a produção transportada no ano. Atrelada ao desenvolvimento do setor, a necessidade do aumento da capacidade de carga das vias impulsionou a realização de investimentos em melhorias operacionais e na infraestrutura da plataforma ferroviária, como aumento do carregamento e do volume de tráfego, acréscimo de velocidades praticadas e desenvolvimento de projetos para expansão da malha com duplicação das vias existentes e criação de novos trechos.

Frente às proposições para aumento de carregamento nas linhas operantes para transporte de um maior volume de material, é necessário o reforço destas vias e uma criteriosa investigação da capacidade de carga do subleito. Na engenharia ferroviária, a investigação do subleito é considerada um elemento fundamental para a garantia da qualidade do desempenho do pavimento e a operação segura e econômica dos veículos ferroviários. Além disso, o conhecimento geotécnico e mecânico dos solos que o compõe é o primeiro passo para a otimização da manutenção e para os projetos de restauração do pavimento ferroviário. Conforme apontado por Brown (1996), a avaliação estrutural do pavimento é resultado da análise da interação complexa entre as camadas e seus respectivos materiais constituintes sob a ação de um carregamento ocasionado pela passagem do veículo.

Medina et al. (2015) apontam, em seu estudo, que as camadas dos pavimentos devem ser compostas por materiais adequados e que atendam aos critérios propostos no modelo de análise do pavimento. No Brasil, os critérios para seleção de materiais para a pavimentação, tanto para os sistemas rodoviário e ferroviário, advêm das normas técnicas e manuais do DNIT que consideram as classificações tradicionais de materiais baseadas nos parâmetros físicos como granulometria, limites de consistência (limite de liquidez e índice de plasticidade) e Índice de Grupo. Os principais métodos para a classificação de solos são o Sistema Unificado de Classificação de Solos, SUCS, desenvolvido para projetos de aeroportos na década de 40, e o 'Transportation Research Board', TRB, elaborado na década de 20 e normalizado pela AASHTO (American Association of State Highway and Transportation Officials). Em muitas situações, a adoção desses critérios, que são muito restritivos para os solos brasileiros, acarretam em maiores distâncias de transportes e, consequentemente, maior impacto ambiental associado à implantação das obras de infraestrutura.

Nogami et al. (2009) abordam que alguns solos de ambientes tropicais não atendem aos critérios de especificação de projeto baseados nessas metodologias de classificação, apesar de apresentarem bom desempenho mecânico. Associada à busca de materiais para atender a expansão dos meios de transporte, $\mathrm{e}$ à impossibilidade da utilização de jazidas próximas pelo não atendimento da classificação técnica americana, o estudo e a avaliação aprofundada do comportamento mecânico de solos tropicais apresentam uma nova 
abordagem para utilização do material nas camadas de pavimentação. Nogami et al. (1979) analisaram que para regiões tropicais seria importante realizar determinações de suporte e expansão do ensaio CBR (California Bearing Ratio, ou ISC, Índice de Suporte Califórnia) para diversas condições de umidade de compactação, imersão, sobrecarga e energias de compactação. Em 1981, os mesmos autores publicaram no I Simpósito Brasileiro de Solos Tropicais em Engenharia uma nova metodologia de estudo e classificação geotécnica para solos denominada MCT (Miniatura, Compactada, Tropical) (NOGAMI et al., 1981).

Delgado (2007) evidenciou a necessidade de um sistema de classificação especial para os solos tropicais, visto que algumas das características físicas desses materiais não são devidamente contempladas no sistema de caracterização tradicional. Entre as razões, evidencia-se que: i) as agregações dos finos induzem a resultados distorcidos de distribuição granulométrica; ii) a massa de solo residual 'in situ' pode revelar uma sucessão de materiais que não são devidamente discriminados pelos ensaios tradicionais, baseados em solos transportados; e iii) os métodos tradicionais focam nas propriedades do solo no estado deformado, onde são preservados a textura e os constituintes minerais, porém, perdendo-se a estrutura original do solo. Sendo assim, destaca-se a necessidade da realização de ensaios complementares laboratoriais e em campo que permitam uma melhor classificação e avaliação representativa das características físicas e mecânicas do solo em estudo.

Nesse contexto, o objetivo deste estudo foi realizar a caracterização geotécnica em campo e em laboratório dos solos de um trecho da Estrada de Ferro Carajás (EFC), e classificar os solos segundo os sistemas tradicionais SUCS e TRB e segundo o método para avaliação de solos tropicais, MCT. As classificações permitem, assim, sistematizar o estudo dos solos voltado às aplicações em infraestrutura, diferenciar os tipos de solos a partir de diversos parâmetros e agrupá-los conforme as características semelhantes. Além disso, os sistemas classificatórios auxiliam na estimativa do comportamento do material e da sua capacidade de suporte, bem como orientam a execução de investigações geotécnicas adicionais.

\section{METODOLOGIA}

\section{Programação das investigações}

Com o objetivo de atender a demanda crescente da carga transportada, especialmente a de minério de ferro, foi desenvolvido o projeto para a duplicação e o aumento da capacidade de carga da Estrada de Ferro Carajás. A duplicação prevista ocorre com a interligação dos pátios de cruzamento e a remodelação das linhas existentes, de modo a formar uma segunda linha, paralela à principal, com a composição trafegando ora sobre a linha duplicada, ora sobre a linha paralela do pátio de cruzamento. Assim, o conceito de pátio de cruzamento extingue-se, e a via passar a operar como uma estrada de ferro de linha dupla.

A fase inicial do estudo baseou-se na visita técnica em campo, e na realização de sondagens e de inspeção visual ao longo do traçado da linha a ser duplicada para o levantamento prévio dos componentes da superestrutura e da infraestrutura da via permanente. Os 54 pátios que compõem a extensão da via foram analisados, separadamente, quanto ao material encontrado no subleito. Em seguida, definiu-se um trecho 
considerado representativo (isto é, um trecho com seções sequenciais com mesmas características geométricas e com camadas provenientes do mesmo material) para a realização dos ensaios geotécnicos deste estudo, e para gerar a base de dados necessária para a condução de ensaios adicionais para a avaliação da capacidade de suporte do trecho duplicado (CAMPOS, 2019).

Após a avaliação prévia dos pátios existentes, determinou-se o Pátio 14 como o trecho experimental deste trabalho por apresentar, pela análise visual, um trecho sequencial constituído do mesmo material na camada de subleito. Conforme apresentado pela Figura 1, de modo distinto ao encontrado nos outros pátios (materiais de estrutura geotécnica distribuídos uniformemente na camada), o Pátio 14 apresentou uma camada de estrutura heterogênea, composta por faixas de materiais de diferentes texturas e colorações, observadas pela análise tátil-visual. Dessa forma, a caracterização geotécnica do material do trecho selecionado - dessemelhante aos solos dos outros pátios, e em especial, aos dos materiais encontrados na literatura geotécnica - fornece os parâmetros básicos que permitem a classificação do solo e a estimativa da capacidade de suporte do trecho, além de apresentar uma relevante investigação que serve como subsídio para a comunidade geotécnica.

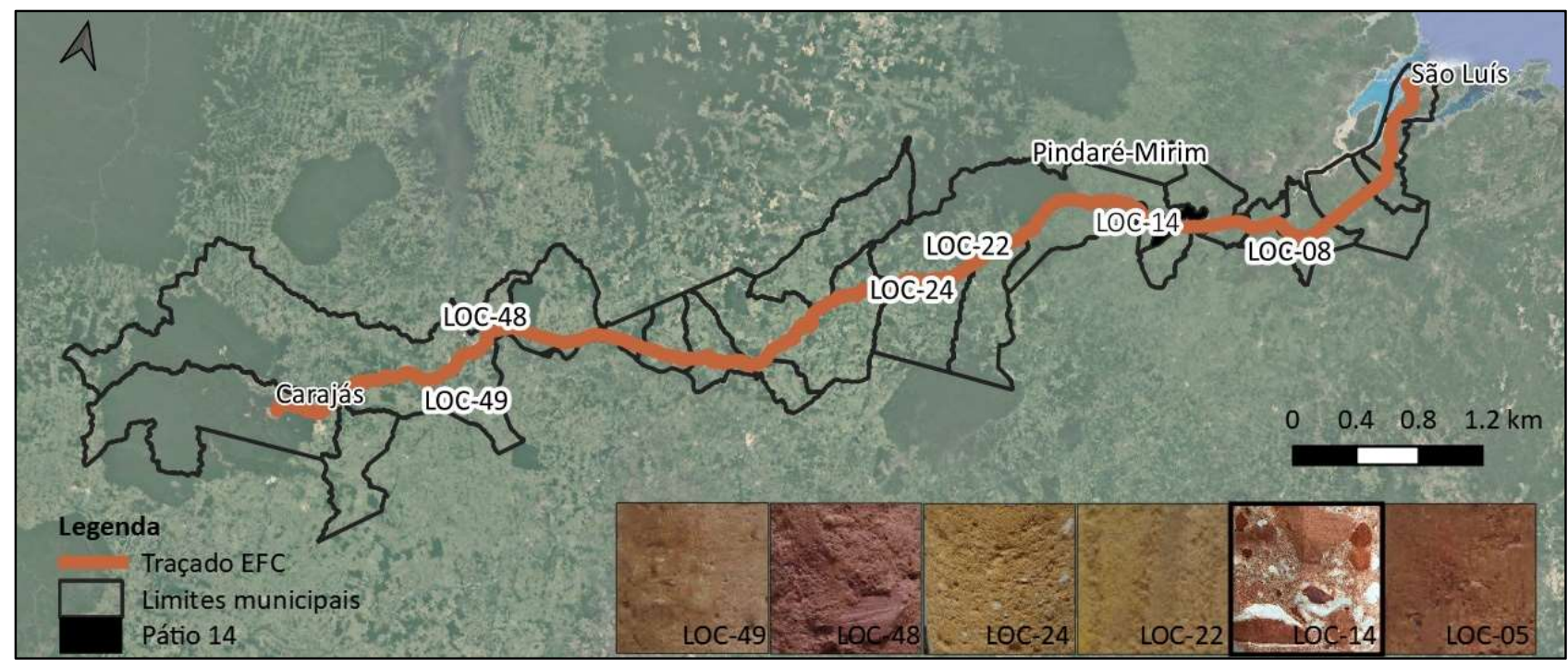

Figura 1: Exemplos de materiais encontrados nos pátios da EFC.

\section{Descrição do local}

O Pátio 14 ( $k m$ 211,908 ao km 216,400) é um trecho integrante da Estrada de Ferro Carajás que percorre o município de Pindaré-Mirim (Figura 2) no estado do Maranhão, Mesorregião Oeste do Maranhão, Microrregião de Pindaré. O município de Pindaré-Mirim está situado na zona de transição climática do Estado do Maranhão, marcado pelo clima tropical Aw (Tropical com estação seca) na porção Sudoeste e Am (Tropical Monçônico) a Nordeste. As temperaturas são elevadas em todo ano, com médias mensais superiores a $26,9^{\circ} \mathrm{C}$ e pico de $29,1^{\circ} \mathrm{C}$ em outubro, e a média anual pluviométrica é de $1.681 \mathrm{~mm}$ (ALVARES et al., 2013).

A geologia local do trecho se enquadra na Formação Itapecuru marcada por arenitos avermelhados, de granulação fina média com presença de níveis argilosos, siltificações e pouca cobertura de solos laterizados. O ambiente de alto grau de intemperismo contribui para a transformação dos arenitos ferruginosos em formações de horizontes plínticos e concreções ferruginosas. A pedologia do município é 
marcada pela ocorrência restrita de Neossolos Flúvicos próximos ao curso do rio Pindaré e por Plintossolos Háplicos, integrando majoritariamente a extensão municipal (CPRM, 2011).

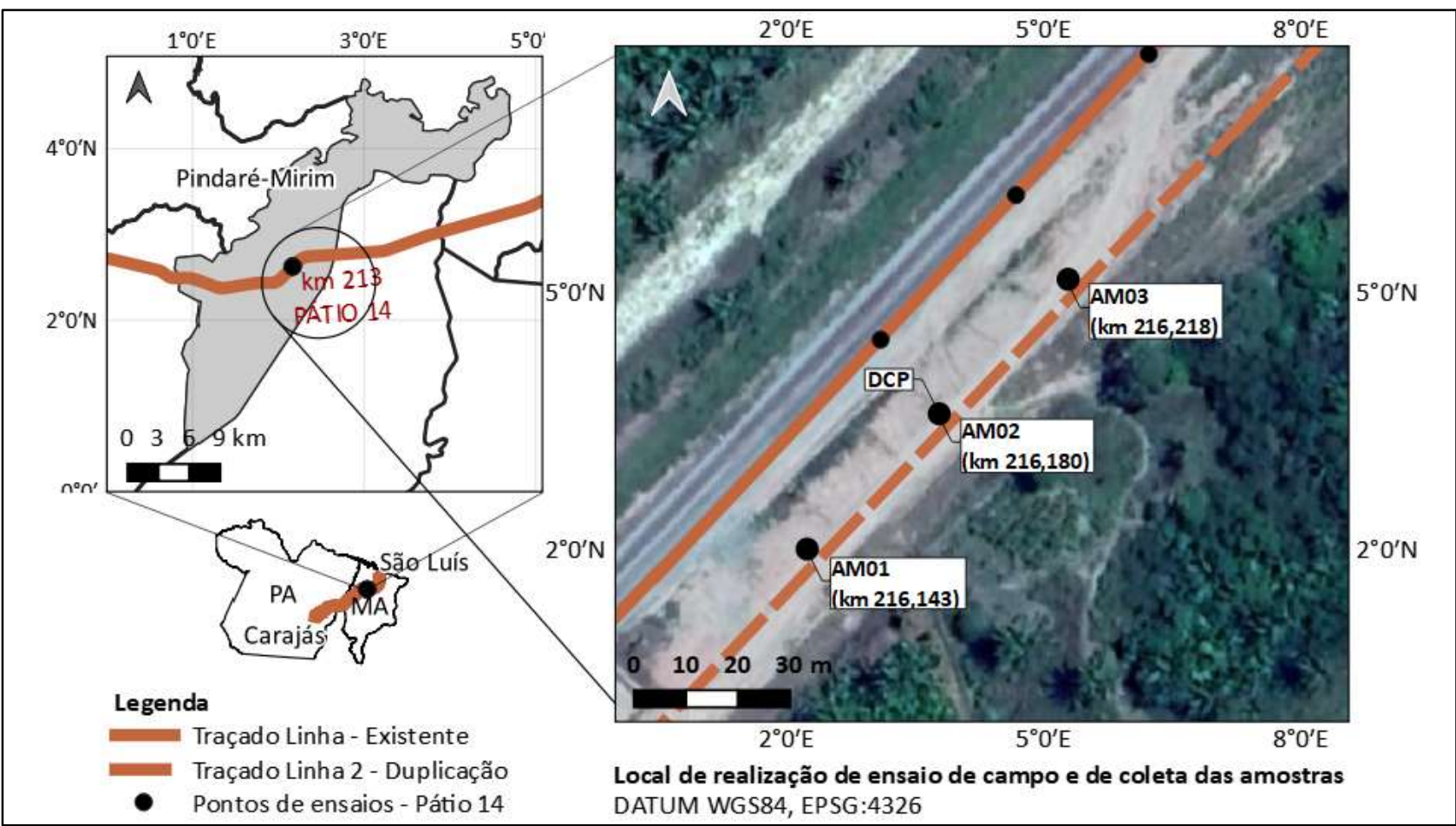

Figura 2: Localização da Estrada de Ferro Carajás e dos pontos de realização de ensaios de investigação geotécnica.

Os solos do trecho analisado foram classificados como Plintossolos, e apresentaram, pela análise visual, mosqueados em colorações diferentes, entremeados por material mineral de coloração ferruginosa denominada plintita. Os horizontes plínticos surgem dentro de $40 \mathrm{~cm}$ da superfície e são constituídos por uma mistura de argila com grãos de quartzo e outros minerais que, após vários ciclos de umedecimento e secagem, consolidam-se irreversivelmente. A classe dos Plintossolos compreende os solos formados sob condições de restrição à percolação da água, sujeitos ao efeito temporário de excesso de umidade (EMBRAPA, 2006). $O$ impedimento à livre drenagem é favorecido pela localização das amostras no aquífero Itapecuru que resulta em camadas sujeitas à umidade local próxima a condição de saturação ou saturadas por grandes períodos do ano, mesmo nos meses de baixa pluviosidade.

Conforme apresentado na Figura 2, a fase de investigação e caracterização dos solos do trecho do Pátio 14 constou com a execução de ensaio do Cone de Penetração Dinâmica (DCP) em campo em um ponto intermediário do trecho $(\mathrm{km} 216,180)$ e com a retirada de amostras em três locais do trecho $(\mathrm{km} 216,143$; km 216,180; km 216,218) para a realização de ensaios laboratoriais. O programa experimental seguiu o plano de sondagens e de investigações previsto pela Instrução de Serviço Ferroviário para Estudos Geotécnicos, ISF-207 (DNIT, 2015), que prevê a realização de ensaio em uma amostra representativa (ou em um ponto do trecho, para o caso dos ensaios em campo) para cada horizonte de material que não ocorra variação. Assim, foram executados os ensaios de DCP, CBR e expansibilidade em um ponto representativo; e devido à heterogeneidade acentuada dos solos identificada pela análise tátil-visual, optou-se pela realização dos ensaios de caracterização física e MCT nas três amostras. 


\section{Investigação de campo}

O ensaio de DCP é usado para avaliar, de forma contínua, o perfil de resistência de camadas de solo em seu estado natural ou em materiais compactados (ALSHIBLI et al., 2005). Padronizado pela norma internacional ASTM D 6951-18 (ASTM, 2018), o ensaio fornece a profundidade penetrada por golpe (DN, em $\mathrm{mm} /$ golpe) exercida no solo em função de sucessivos impactos de massa de 8 (oito) kg em um pistão de 1,00 m. Para a avaliação do pavimento do trecho, o ensaio foi executado no km 216,180 do traçado da Linha 2 (a 2,80 m de distância do eixo da Linha 1), abaixo da camada de lastro, como observado na Figura 3.

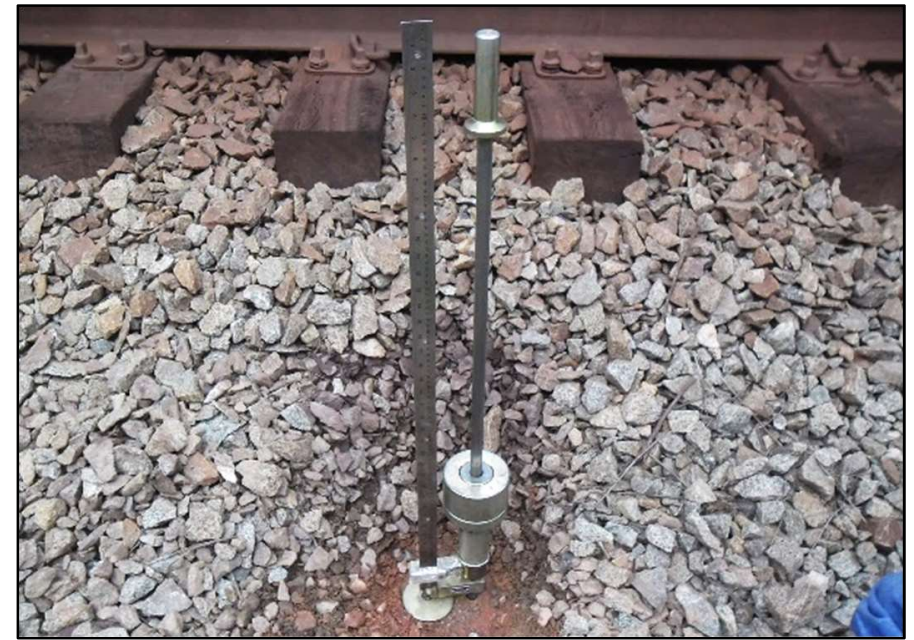

Figura 3: Ensaio DCP executado no km 216,180 do traçado da linha 2.

Após o ensaio em campo, sucede-se a análise dos dados em laboratório, o que permite inferir, por meio do índice de penetração dinâmica, a estimativa das espessuras das camadas do pavimento e dos parâmetros de resistência do material nas condições 'in situ'.

\section{Coleta das amostras}

Na sequência da investigação geotécnica em campo, foram coletadas as amostras do subleito, a 25 $\mathrm{cm}$ abaixo da camada de lastro, em três pontos do trecho (vide Figura 2), e de acordo com a posição na extensão da via, receberam a seguinte numeração para codificação: a) AM01 - km 216 + 143 ; b) AM02 - km 216 + 180 e; c) AM03 - km 216 + 218. As amostras de solos do subleito ferroviário coletadas no trecho foram encaminhadas para o Laboratório de Geotecnia da Empresa Pattrol, em Belo Horizonte/MG, onde procederam-se os ensaios geotécnicos laboratoriais. Esta etapa contemplou a realização de ensaios de laboratório segundo a ISF-207 (DNIT, 2015). Sendo assim, foram executados a caracterização geotécnica através da metodologia tradicional (granulometria completa, Limites de consistência e densidade real dos grãos) e os ensaios de CBR e de expansibilidade. Em complemento, em virtude da natureza dos solos da região em estudo, tipicamente tropical, procedeu-se a classificação dos solos pelo método de classificação de solos tropicais (MCT), pelos ensaios de Mini-MCV, perda de massa por imersão e MCT expedito.

\section{Caracterização física}

A preparação das amostras constou com a secagem do material em estufa a $60^{\circ} \mathrm{C}$ por $24 \mathrm{~h}$ até a 
redução à umidade próxima à higroscópica, seguida do destorroamento dos grãos para homogeneização do solo pelos procedimentos da norma NBR 6457 (ABNT, 2016). A caracterização física foi determinada pelos ensaios de granulometria por peneiramento e sedimentação, conforme a norma DNER-ME 080/94 (DNER, 1994a), e limite de liquidez e de plasticidade, segundo DNER-ME 122/94 (DNER, 1994b) e DNER-ME 082/94 (DNER, 1994c), respectivamente. A Figura 4 apresenta as principais fases dos ensaios de caracterização após a preparação das amostras: (a) série de peneiras, (b) ensaio de sedimentação e (c) solo separado para a obtenção da umidade após ensaio de limite de liquidez e de plasticidade.
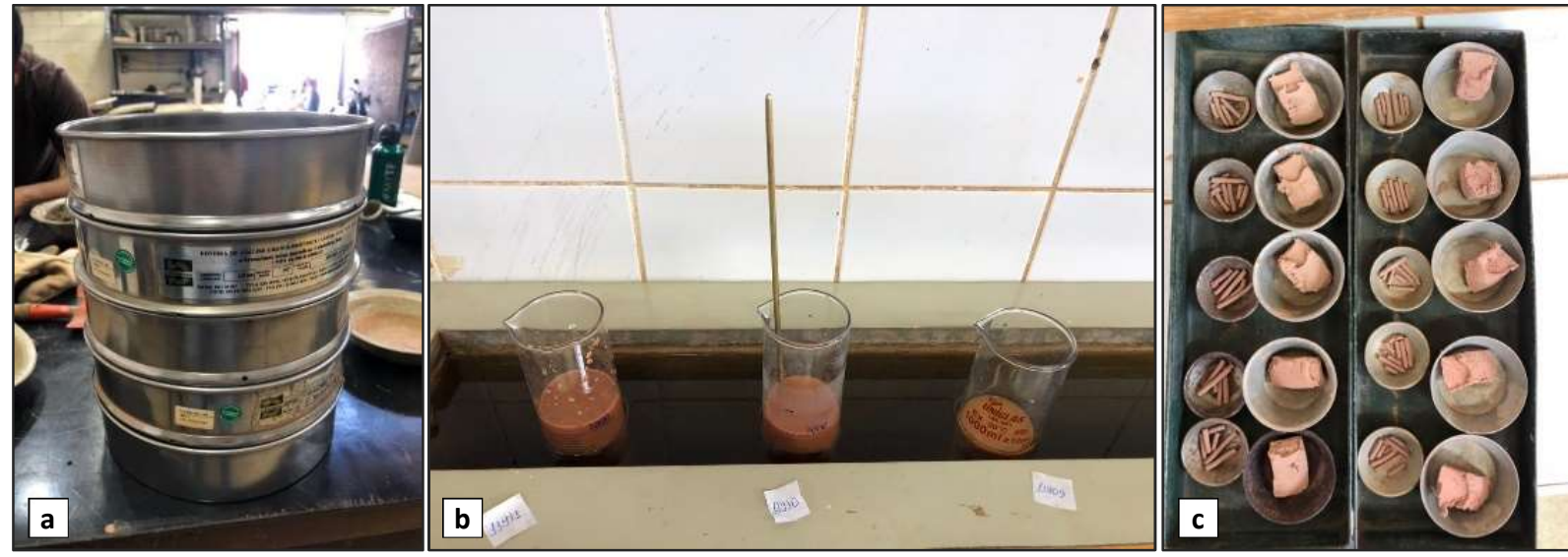

Figura 4: Caracterização física do solo: (a) conjunto de peneiras para granulometria por peneiramento, (b) ensaio granulométrico por sedimentação e (c) solo após ensaios de limites de consistência. Fonte: Campos (2019).

Na sequência, foi executado o ensaio para determinação da densidade real dos grãos pelo método do picnômetro em concordância com a padronização da norma DNER-ME 093/94 (DNER, 1994d).

\section{Método MCT}

Para a classificação dos solos segundo a metodologia MCT, foram executados os ensaios de miniMCV e de perda de massa por imersão padronizado pelas normas DNER-ME 256/94 (DNER, 1994e) e DNER258/94 (DNER, 1994f). Os solos foram passados na peneira no10 e homogeneizados em cinco porções de $500 \mathrm{~g}$, com o teor de umidade variando $4 \%$ entre as porções. Convencionou-se uma umidade intermediária arbitrária e, à medida que o teor de umidade era variado e os dados eram lançados nas planilhas de MCT, analisou-se a ascensão ou declínio da curva conforme o aumento e diminuição da quantidade de água para a definição do intervalo de umidade do ensaio. Posteriormente, as porções de solo foram introduzidas nos cilindros de compactação de 50 mm (Figura 5.a), e realizou o ensaio de Mini-MCV por meio do equipamento de compactação Mini-Proctor (Figura 5.b).

Destarte, procedeu-se o ensaio de perda de massa por imersão a fim de avaliar o potencial de erodibilidade do solo sob a ação da água quando compactado e parcialmente confinado. A preparação do ensaio consistiu na extrusão parcial de $10 \mathrm{~mm}$ do solo compactado do cilindro, seguida da submersão das amostras em água em um período mínimo de 20 horas. Nos primeiros minutos de ensaio, atentou-se para observação de eventuais alterações no comportamento do solo, tais como desprendimento, inchamento, trincamento ou desagregação; e quaisquer peculiaridades ocorridas foram analisadas e anotadas. Por fim, 
após 24 horas de imersão (Figura 5.c), as cápsulas com material desprendido foram recolhidas e encaminhadas à secagem.
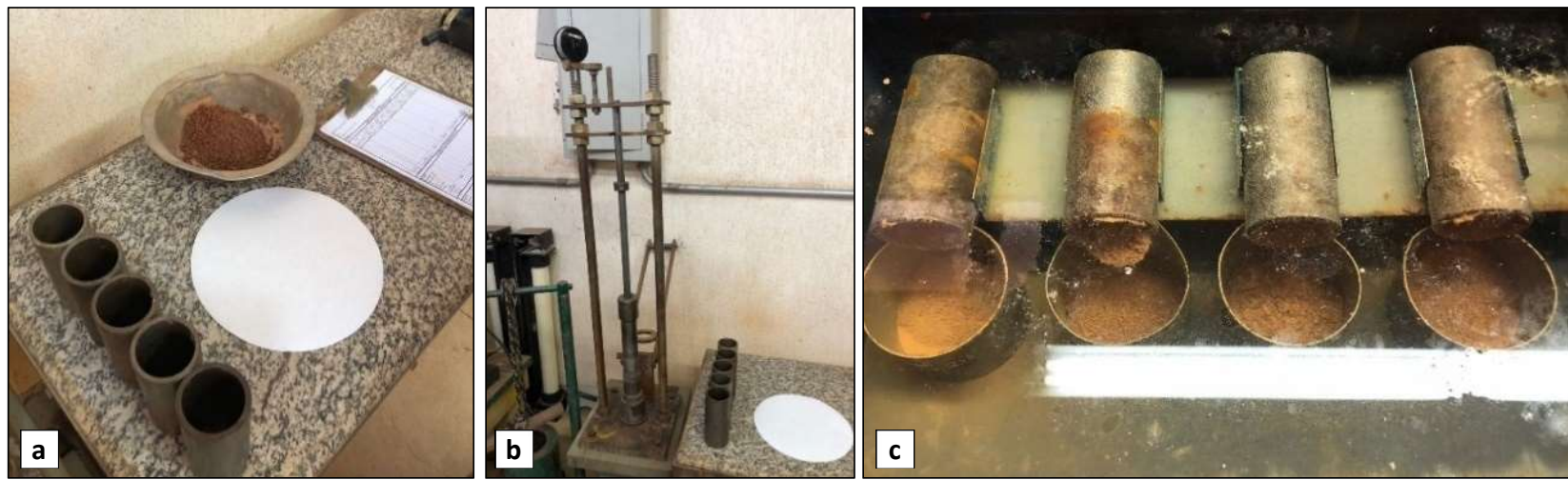

Figura 5: Método MCT: (a) cilindros para preparação da amostra, (b) equipamento de compactação Mini-Proctor usado no ensaio Mini-MCV e (c) e perda de massa das amostras após 24 horas de imersão.

A perda de massa por imersão (\%Pi) - para cada teor de umidade - pode ser expressa pela razão entre a massa do solo seco desprendido e a massa de solo seco correspondente aos $10 \mathrm{~mm}$ salientes inicialmente. Para fins classificatórios, o valor da perda de solo característica da amostra ( $\mathrm{Pi}$ ) é obtido, graficamente, pela interpolação da curva traçada pelas variações das porcentagens de Mini-MCV no eixo das abscissas; e a perda de massa por imersão, nas ordenadas.

Concordante aos procedimentos propostos por Nogami et al. (1995), o Método MCT Expedito ou Método das Pastilhas foi efetuado para confirmação dos resultados obtidos no ensaio anterior. O método baseia-se na identificação expedita de solos tropicais, segundo índices empíricos de contração e penetração e avaliações qualitativas através de procedimentos simples e rápidos.

O processo de ensaio consistiu na moldagem do solo, com consistência plástica, em três esferas e três pastilhas em anéis de aço de $20 \mathrm{~mm}$ de diâmetro. As amostras foram então levadas à estufa, e após a secagem, foram retiradas e se verificou a contração diametral das pastilhas. Em seguida, submeteram-se as pastilhas ao processo de reabsorção de água, e a resistência à penetração foi determinada pelo equipamento penetrômetro padrão. Na Figura 6, são apresentados os procedimentos referidos.
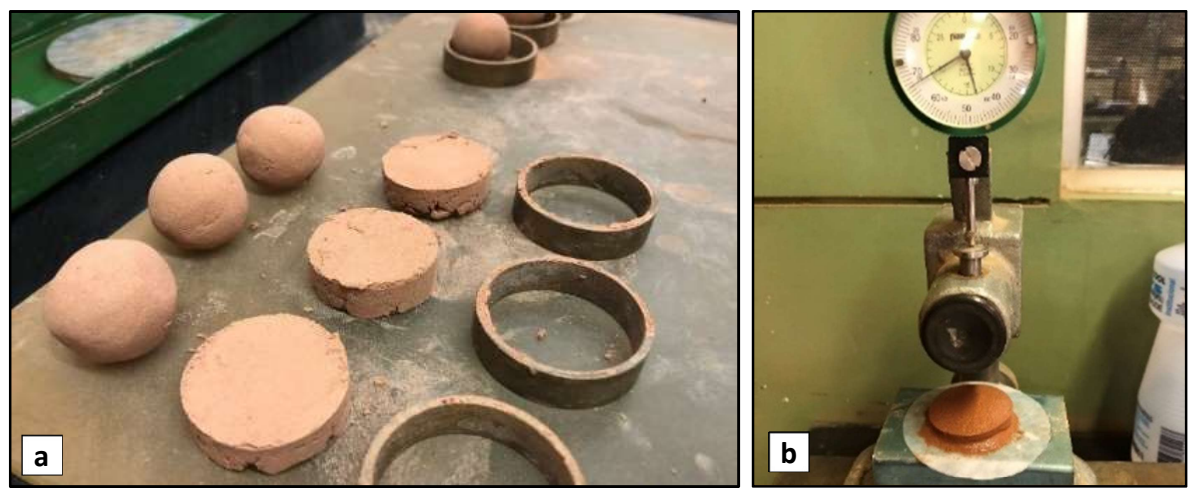

Figura 6: MCT expedito: (a) esferas e pastilhas após secagem; (b) medição da resistência à penetração após absorção.

As esferas foram avaliadas quanto à resistência ao esmagamento e quanto ao tempo de reabsorção e aspecto após submersão em água. Os dados foram analisados, e identificou-se a concordância entre os métodos de classificação para solos tropicais. 


\section{Capacidade de suporte e expansibilidade}

Por fim, o ensaio de CBR foi realizado com o objetivo de identificar a capacidade de suporte dos solos e determinar a expansão na região em estudo. A partir dos parâmetros de compactação do solo, iniciou-se tais ensaio na amostra AM 02 (km 216,180) sob compactação na energia do Proctor Normal, consoante com as especificações da NBR 9895 (ABNT, 2017).

\section{RESULTADOS E DISCUSSÃO}

\section{Caracterização em campo}

O ensaio DCP (Figura 3) permite correlacionar os valores de penetração do solo 'in situ' com a resistência da camada e sua espessura. Para a análise dos resultados do ensaio, os valores foram plotados em um gráfico de dispersão 'Penetração acumulada X Número de Golpes' (Figura 7) para a realização da regressão linear simples. Os pontos sequenciais que apresentaram valores semelhantes de penetração acumulada por golpe foram agrupados por trechos, e foram definidas equações ajustadas com altos valores de $\mathrm{R}^{2}$, o que indica o comportamento claramente linear para os trechos selecionados. A linearização dos valores aponta para a sucessão de pontos com resistência aproximada (aqui representada pela penetração acumulada por golpe, DN) que caracterizam seguimentos constituídos pelo mesmo material geotécnico, ou seja, as camadas do pavimento. Dessa forma, estabeleceram-se três segmentos para a estrutura do pavimento analisado conforme as profundidades: de 0 a $23 \mathrm{~cm}$ (camada 1, Sublastro); de 23 a $83 \mathrm{~cm}$ (camada 2, Subleito 1); e de 83 a $90 \mathrm{~cm}$ (camada 3, Subleito 2). Destacam-se como limitações do ensaio de DCP a execução em 1,00 m inicial do pavimento - limitada pela altura do pistão - e a interrupção do teste se atingida uma camada impenetrável. Sendo assim, a estimativa da espessura da camada do Subleito 2 apresentada no gráfico tange às limitações do ensaio, e pode apresentar a dimensão variável em campo.

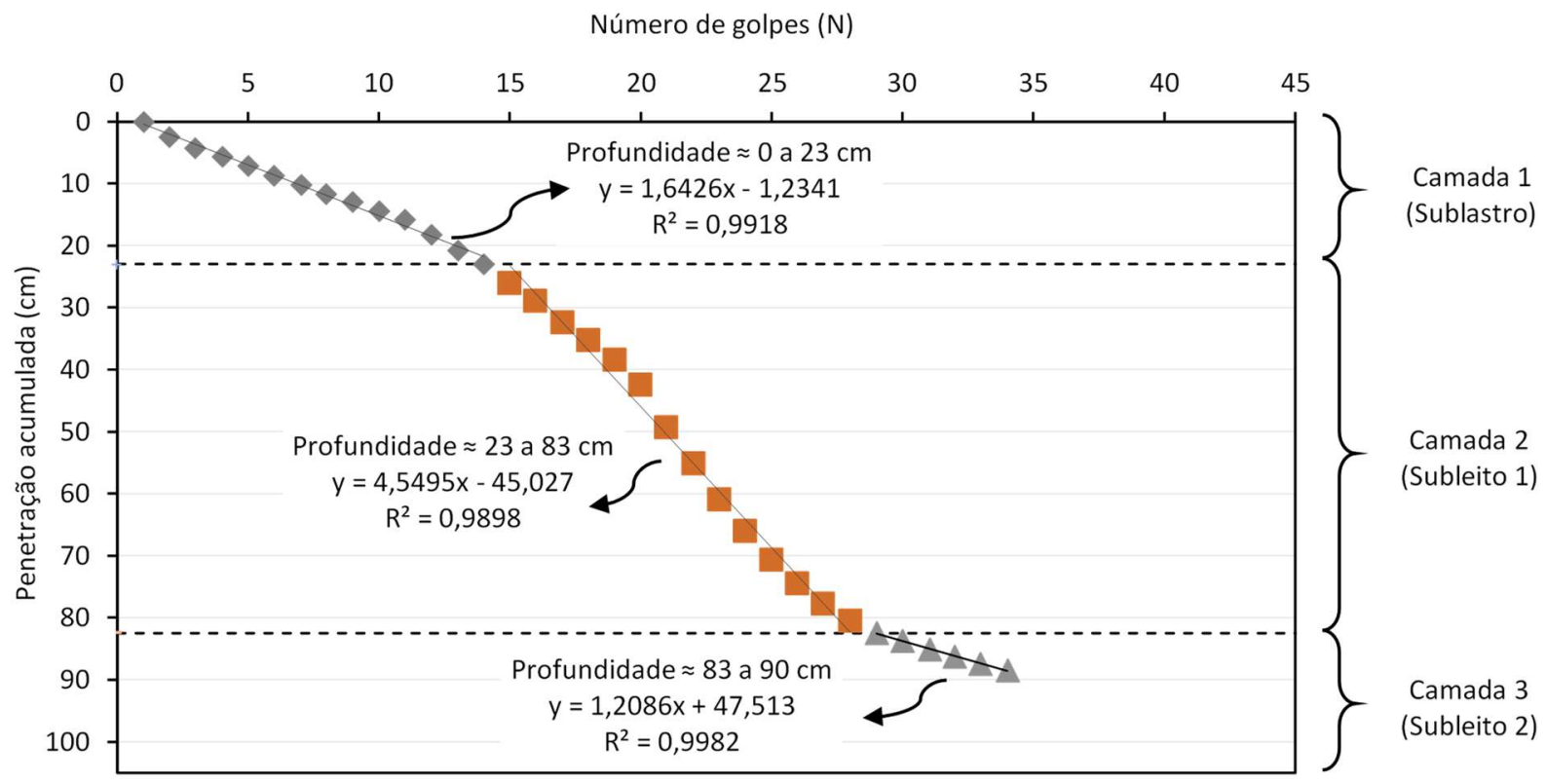

Figura 7: Estimativa da estrutura do pavimento e da espessura das camadas com base no índice de penetração por golpe (DCPI, mm/golpe) determinado pelo ensaio de DCP executado no trecho, $\mathrm{km} \mathrm{216,180.}$ 
Tais espessuras estimadas pelo ensaio de DCP são influenciadas pela variabilidade das dimensões das camadas na seção longitudinal da via. Assim, os valores encontrados foram arredondados para cima a múltiplos de $5 \mathrm{~cm}$, definindo a seção transversal da via apresentada na Figura 8. O pavimento do trecho em estudo é caracterizado por uma camada de lastro com $35 \mathrm{~cm}$ de espessura (identificada pela análise em campo), sobrejacente ao sublastro de $25 \mathrm{~cm}$ de espessura, assentados sobre o subleito 1 de espessura de 60 cm e sobre um subleito 2 que constitui o terrapleno natural da via.

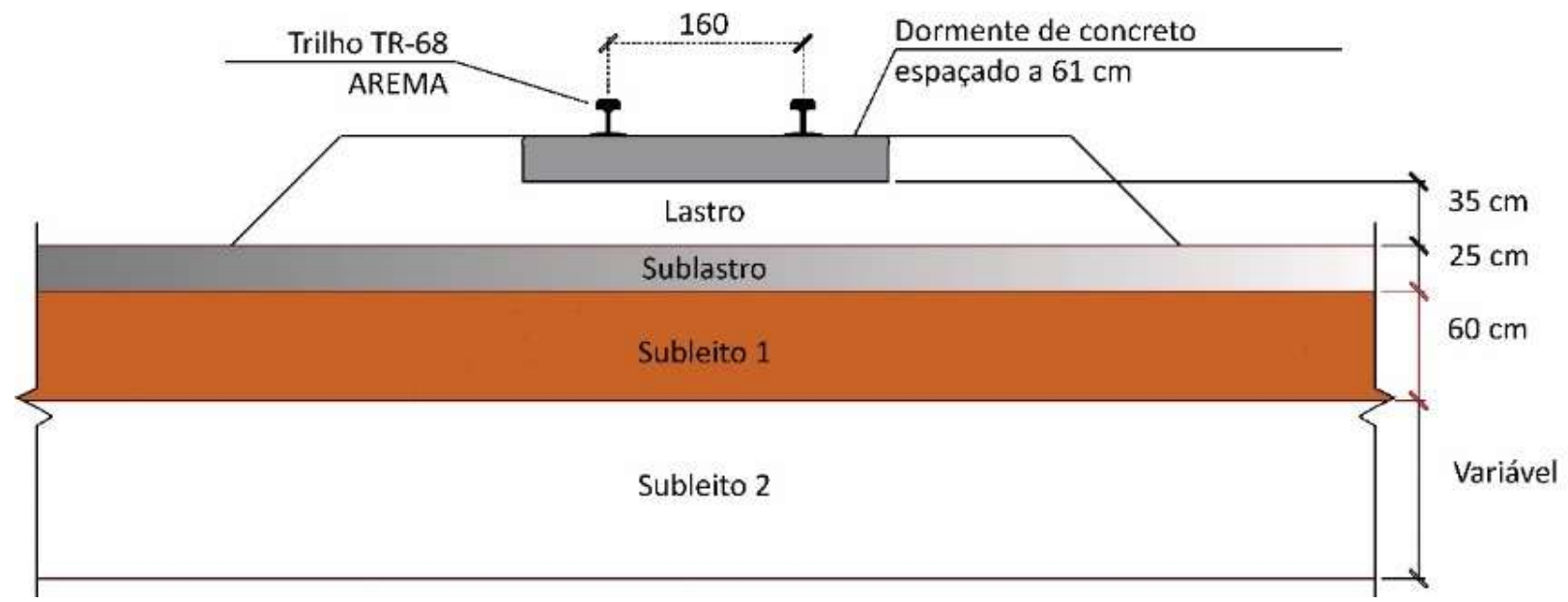

Figura 8: Seção típica do pavimento ferroviário do trecho do Pátio 14.

Os resultados da penetração acumulada por golpe (DN) das camadas foram usados para a estimativa de um CBR teórico com base em modelos preditivos da literatura. Foram usadas as correlações de Webster et al. (1992), usado para diferentes tipos de solos; de Angelone et al. (1991), formulada a partir de amostras de solos arenosos finos A-4 e A-6 argentinos; e de Cardoso et al. (1998), fundamentada nos solos A-7-6, A-4 e A-2-4 de Santa Catarina, conforme exposto na Tabela 1.

Tabela 1: Resultados do ensaio de DCP e estimativa do CBR a partir das correlações teóricas.

\begin{tabular}{|c|c|c|c|c|c|c|}
\hline \multirow[t]{3}{*}{ Equação } & \multicolumn{2}{|c|}{ Camada 1 (Sublastro) } & \multicolumn{2}{|c|}{ Camada 2 (Subleito 1) } & \multicolumn{2}{|c|}{ Camada 3 (Subleito 2) } \\
\hline & DN & CBR & DN & CBR & DN & CBR \\
\hline & (mm/Golpe) & (\%) & (mm/Golpe) & (\%) & (mm/Golpe) & (\%) \\
\hline $\log C B R=2,550-1,140 \log$ DN (Webster et al.,1992) & \multirow[t]{4}{*}{16,43} & 13 & \multirow[t]{4}{*}{45,50} & 4 & \multirow[t]{4}{*}{12,09} & 18 \\
\hline $\log C B R=2,563-1,050$ log DN (Angelone et al., 1991) & & 19 & & 7 & & 27 \\
\hline $\mathrm{CBR}=512,64 \cdot \mathrm{DN}^{-1,25}$ (Cardoso et al., 1998) & & 16 & & 4 & & 23 \\
\hline Média & & 16 & & 5 & & 23 \\
\hline Coef. de Variação (CV) & - & $19 \%$ & - & $35 \%$ & - & $20 \%$ \\
\hline
\end{tabular}

Como apontado na tabela acima, as camadas 1 e 3 apresentaram os valores de DN de 16,43 e 12,09 $\mathrm{mm} /$ golpe, respectivamente. Os valores de CBR estimados pelas correlações foram entre 13 e $19 \%$, para o sublastro, e entre 18 e $27 \%$ para o subleito 2. Nota-se que a resistência do subleito 2 (ou terrapleno natural) é superior à da camada de sublastro. Ou seja, neste trecho, o terrapleno natural (subleito 2) é composto por um material com capacidade de suporte mais elevada que o constituinte da camada de sublastro, que, por estar mais próximo ao local de aplicação de carga, deve absorver as maiores tensões provenientes do carregamento. Já a maior penetração acumulada por golpe e, consequentemente, a menor resistência do pavimento ocorre no subleito 1 . A camada apresentou o DN de 45,50 mm/golpe e o CBR inferior a $10 \%$ (considerado muito baixo) com o maior coeficiente de variabilidade entre as camadas analisadas. Do subleito 
1 foram coletadas as amostras para a execução dos ensaios geotécnicos posteriores para caracterização do material, incluindo o de CBR, o que permite a comparação do valor encontrado a partir dos modelos preditivos pela literatura com o ensaiado em laboratório.

\section{Índices físicos}

Para a classificação tradicional das três amostras coletadas na mesma camada do pavimento ferroviário (subleito 1), procederam-se os ensaios de análise granulométrica por peneiramento e por sedimentação, de limites de consistência e de densidade real dos grãos, cujos resultados são apresentados na Tabela 2.

Tabela 2: Índices físicos das amostras: composição granulométrica, limites de consistência e classificações SUCS e TRB.

\begin{tabular}{|c|c|c|c|c|c|c|c|c|c|}
\hline \multirow[t]{2}{*}{ Amostra } & \multirow[t]{2}{*}{ km } & \multicolumn{4}{|c|}{ Fração Granulométrica (\%) } & \multicolumn{3}{|c|}{$\begin{array}{l}\text { Limites de consistência } \\
(\%)\end{array}$} & \multirow[t]{2}{*}{$\begin{array}{l}\text { Densidade Real dos Grãos } \\
\left(\mathrm{g} / \mathrm{cm}^{3}\right)\end{array}$} \\
\hline & & Pedregulho & Areia & Silte & Argila & LL & $\mathbf{L P}$ & IP & \\
\hline AM01 & 216,143 & 0,3 & 55,1 & 24,6 & 20,0 & 27,0 & 17,0 & 10,0 & 2,613 \\
\hline AM02 & 216,180 & 2,8 & 44,0 & 31,9 & 21,4 & 31,0 & 17,0 & 14,0 & 2,625 \\
\hline AM03 & 216,218 & 0,4 & 58,2 & 19,2 & 22,2 & 29,0 & 18,0 & 11,0 & 2,643 \\
\hline \multicolumn{2}{|l|}{ Média } & 1,2 & 52,4 & 25,2 & 21,2 & 29,0 & 17,3 & 11,7 & \\
\hline \multicolumn{2}{|c|}{ Coef. de Variação (CV) } & $118,0 \%$ & $14,3 \%$ & $25,3 \%$ & $5,3 \%$ & $6,9 \%$ & $3,3 \%$ & $17,8 \%$ & \\
\hline
\end{tabular}

Observa-se que a fração de pedregulho exibiu porcentagens pouco expressivas, entre 0,3 e 2,8\%; e as frações de areia e de finos (silte + argila), predominantes na composição granulométrica do material, apresentaram variabilidade significativa nas porcentagens (acima de 10\%), com variações de 44,0 a 58,0 \% para areia (CV = 14,3\%), e 44,0 a 53,3\% para os finos ( $C V=25,3 \%$, para silte; e $C V=5,3 \%$, para argila). Por meio do ensaio de sedimentação com defloculante, a porção fina foi decomposta em frações de silte e argila, tornando-se possível a distinção e a caracterização do comportamento do solo, de acordo com a prevalência siltosa ou argilosa, e a composição completa das curvas granulométricas do material (Figura 9.a).
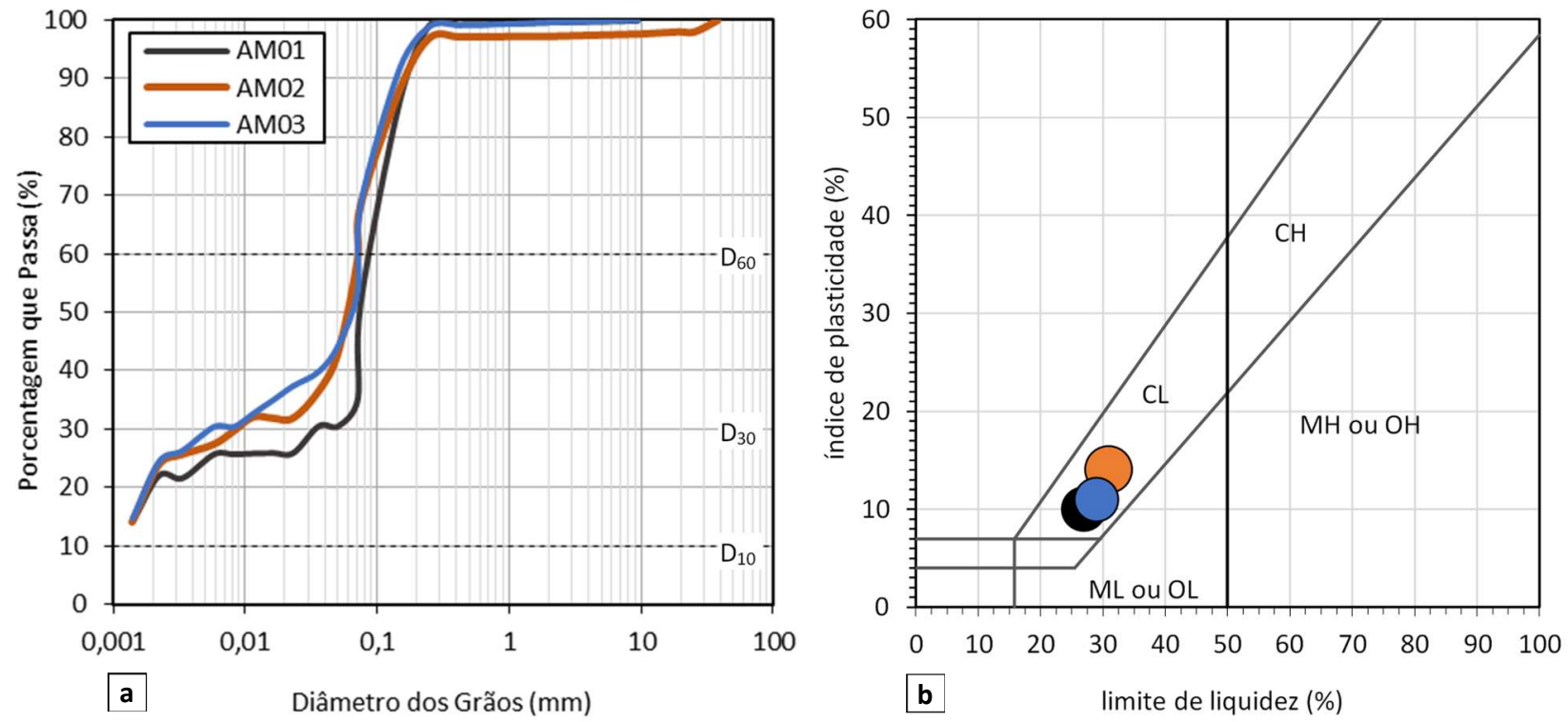

Figura 9: (a) Curva granulométrica das amostras e (b) carta de plasticidade de Casagrande.

De acordo com os dados apresentados, nota-se que as amostras AM 01 e AM 03 exibiram pequenas variações quanto às frações que as compõem. A amostra AM 02, em contraponto, apresentou porcentagem 
de pedregulho superior às demais, e parcela de finos preponderante a de areia - com dominância de silte -, o que justifica o aumento do índice de plasticidade do material desta amostra.

Outros parâmetros que podem ser utilizados para a avaliação do aspecto granulométrico são o coeficiente de uniformidade ( $\mathrm{Cu}$ ) e coeficiente de curvatura (Cc), Tabela 3. O coeficiente de uniformidade corresponde à relação entre os diâmetros dos grãos em que passam $60 \%$ e $10 \%$ dos agregados $\left(D_{60} / D_{10}\right)$, e serve para avaliar a uniformidade da distribuição granulométrica das amostras. Do mesmo modo, o coeficiente de curvatura, expresso pelo $D_{30}{ }^{2} /\left(D_{60} \cdot D_{10}\right)$, indica a forma de distribuição das curvas e permite detectar descontinuidades presentes no conjunto. De acordo com as classificações dos solos consideradas por alguns autores a partir dos coeficientes (PINTO, 2006), todas as três amostras possuem granulometria não-uniforme ( $\mathrm{Cu}>15)$, com composições de grãos de diferentes tamanhos.

Adicionalmente, o coeficiente de curvatura indica que as amostras AM 02 e AM 03 possuem distribuições bem graduadas $(1<\mathrm{Cc}<3)$. Já a AM 01 apresentou descontinuidades na curva, com cerca de $63 \%$ da porção em peso das amostras com tamanhos de partículas entre 0,07 e 0,25 mm, o que representa uma composição mal graduada com $C c \approx 24,5$. A influência da graduação das partículas na resistência e no estado de compactação dos solos foi apontada por diversos estudos (MEDINA et al., 2015; ISRAR et al., 2017; SHI et al., 2018). Em solos bem graduados, o imbricamento das partículas de diferentes tamanhos confere maior resistência à ruptura ao solo. Sendo assim, os solos com distribuição contínua dos grãos (AM 02 e AM 03) tendem a apresentar melhores condições de compactação e de resistência.

Tabela 3: Parâmetros granulométricos das amostras.

\begin{tabular}{|l|l|l|l|l|l|l|l|l|}
\hline Amostra & $\mathbf{\# 2 0 0}(\mathbf{\%})$ & $\mathbf{D}_{\mathbf{6 0}} \mathbf{( m m )}$ & $\mathbf{D}_{\mathbf{3 0}} \mathbf{( m m )}$ & $\mathbf{D}_{\mathbf{1 0}} \mathbf{1}(\mathbf{m m})$ & $\mathbf{C u}$ & $\mathbf{C C}$ & \multicolumn{2}{l|}{ Classificação } \\
\hline AM01 & & & & & & & SUCS & TRB \\
\hline AM02 & 51,6 & 0,085 & 0,050 & 0,001 & 70,8 & 24,5 & CL & A-2-4 \\
\hline AM03 & 68,2 & 0,072 & 0,008 & 0,001 & 59,7 & 0,8 & CL & A-4 \\
\hline
\end{tabular}

Segundo a classificação do TRB, a amostra AM 02 foi classificada como solo granular A-2-4 devido à porcentagem retida na peneira $n^{\circ} 200$ inferior a $35 \%$; já as demais, tratam-se de solos siltosos do tipo A-4. Em relação ao sistema unificado SUCS, todas as amostras classificam-se como argila de baixa plasticidade "CL", ou amostras não plásticas (Figura 9.b). Tais classificações apontam para solos que tendem a apresentar valor como material de fundação de mau a bom pelo grupo de solos SUCS, CL (PASTORE et al., 1998), e comportamento como subleito de sofrível a mau pelos grupos TRB, A-2-4 e A-4 (DNIT, 2006).

\section{Classificação para solos tropicais}

As amostras coletadas foram submetidas ao ensaio de mini compactação tropical e perda de massa por imersão e classificadas segundo a metodologia MCT. Os parâmetros obtidos na classificação MCT são apresentados na Tabela 4. Segundo a classificação MCT, as amostras foram AM 01 e AM 03 foram classificadas como solo não-laterítico arenoso, $\mathrm{NA}^{\prime}$, e amostra $\mathrm{AM}$ 02, como solo não-laterítico siltoso, $\mathrm{NS}^{\prime}$.

\footnotetext{
10 valor de $D_{10}$ foi determinado a partir de interpolação das curvas granulométricas da Figura 9, uma vez que as amostras apresentaram porcentagem passante superior a $10 \%$ na menor dimensão analisada pelo ensaio $(\varnothing 0,0014 \mathrm{~mm})$.
} 
A diferença apontada na classificação confirma os resultados do ensaio de granulometria, onde essa amostra (AM 02) apresentou fração predominantemente fina com maior porcentagem de silte.

Tabela 4: Classificação das amostras segundo Método MCT e Método MCT Expedito (Método das Pastilhas).

\begin{tabular}{|l|l|l|l|l|l|l|}
\hline Amostra & $\mathbf{c}^{\prime}$ & $\mathbf{d}^{\prime}$ & $\mathbf{e}^{\prime}$ & $\mathbf{P i}(\%)$ & Classificação MCT & Classificação Método Expedito \\
\hline AM01 & 0,85 & 43,96 & 1,45 & 261,20 & $\mathrm{NA}^{\prime}$ & $\mathrm{NA}^{\prime}$ \\
\hline AM02 & 1,37 & 43,96 & 1,52 & 306,20 & $\mathrm{NS}^{\prime}$ & $\mathrm{NS}^{\prime}$ \\
\hline AM03 & 0,81 & 19,14 & 1,58 & 291,60 & $\mathrm{NA}^{\prime}$ & $\mathrm{NA}^{\prime}$ \\
\hline
\end{tabular}

A influência do comportamento não-laterítico no desempenho mecânico do solo é alvo de críticas de diferentes autores (DARIVA, 2016; GOMES et al., 2018). Os resultados de estudos apontam que, para solos não-lateríticos do tipo NA' e NS', quanto maior a parcela de finos, o comportamento mecânico do solo tende a ser afetado consideravelmente, podendo resultar em solos com baixa capacidade de suporte.

\section{CBR e expansão}

Por fim, o ensaio de CBR permitiu a avaliação da capacidade de suporte do trecho e a verificação da expansibilidade do solo. Os resultados dos ensaios (Tabela 5) foram relacionados com os valores encontrados pelos modelos preditivos da literatura e com as limitações propostas pela ISF-207 (DNIT, 2015).

Tabela 5: CBR e expansão do solo do subleito, AM 02, km 216,180

\begin{tabular}{|l|l|l|l|l|}
\hline Amostra & Km & Expansão (\%) & \% argila & CBR (\%) \\
\hline AM02 & 216,180 & 2,3 & 21 & 4,0 \\
\hline Limites da ISF-207 (DNIT, 2015) & $<2,0$ & $<35$ & $>10,0$ \\
\hline
\end{tabular}

Ao comparar os valores do CBR teórico da Tabela 1 e o ensaiado da Tabela 5, a correlação de Webster et al. (1992) - usada para solos de diferentes granulometrias - foi a que apresentou maior assertividade ao igualar o valor teórico ao ensaiado (4,00\%). Similarmente, a correlação de Cardoso et al. (1998), para solos A-7-6, A-4 e A-2-4, aproximou-se com um valor estimado de 4,34\%. Já a de Angelone et al. (1991) exibiu um valor previsto discrepante de $6,64 \%$. As correlações analisadas mostraram-se eficientes para a predição do CBR teórico na ausência de execução de ensaios. Entretanto, para melhores estimativas, tais correlações devem ser usadas para os mesmos tipos de solos que os usados para a sua formulação, o que torna as equações de Webster et al. (1992) e de Cardoso et al. (1998) mais adequadas para o solo A-2-4 e A-4 analisado neste estudo.

Quanto à análise dos resultados do ensaio, o valor de CBR apresentado é consideravelmente baixo, inferior ao limite mínimo estipulado para o uso deste material como camada de subleito. Da mesma forma, o valor da expansão excede o previsto pela norma $(<2,0 \%)$, tratando-se de um solo com problemas moderados de expansão. Adicionalmente, para que estes solos tenham um bom desempenho como material de pavimentação, o valor do material passante na peneira \#200 deve ser inferior a 35\%. Como visto anteriormente, esses valores são superiores a 35\% e chegam a quase $70 \%$. Portanto, de acordo com as padronizações da IF-207 (DNIT, 2015) referentes a esses ensaios, a utilização deste solo como camada de subleito seria inviabilizada.

A utilização do CBR para a avaliação da capacidade de carga do pavimento se associa aos critérios de 
ruptura do subleito. Entretanto, para as condições reais de campo, a condição de ruptura não dever ser admitida para o pavimento. Assim, as camadas devem ser analisadas para que sejam solicitadas, de forma predominante, no regime elástico e plástico; a fim de limitar as deformações excessivas pela aplicação de cargas repetitivas, a deformação permanente ou ruptura por cisalhamento e a expansão volumétrica em excesso, no caso de solos expansivos. Além disso, Fortunato (2005) acrescenta que os ensaios estáticos, tipo CBR, não refletem, necessariamente, a deformabilidade dos materiais, ao desconsiderar os efeitos do estado de tensão 'in situ' e do tempo de solicitação do carregamento imposto pela passagem dos trens.

Nesse contexto, além dos ensaios estáticos para a avaliação da capacidade de suporte da via (CBR e DCP), sugere-se a execução de ensaios adicionais em trabalhos futuros para avaliar o comportamento mecânico (resiliente e permanente) do solo quando submetido a tensões cíclicas que simulam a ação dos tráfegos de veículos. Esse tipo de análise é considerado ainda mais relevante nos estudos dos comportamentos geotécnicos de solos tropicais; que não condizem, muitas vezes, com os valores padronizados em função das classificações tradicionais contidas na literatura técnica e do CBR.

\section{CONCLUSÕES}

O melhor emprego de solos tropicais na infraestrutura ferroviária contribui com o menor impacto ao meio ambiente, redução da movimentação dos terraplenos na implantação da plataforma, menores custos com remanejamentos e minimização das interferências na circulação dos trens. Assim, este artigo teve como objetivo principal a avaliação da capacidade de suporte de solos locais de um trecho da duplicação da Estrada de Ferro Carajás a partir de sondagens geotécnicas em campo e laboratoriais.

O plano de investigação constou com uma avaliação prévia por análise tátil-visual dos 54 pátios que compõem a malha e a definição do Pátio 14 como o trecho experimental por atender as premissas do estudo. Em campo, executou-se o ensaio de DCP a fim de estimar a seção do pavimento do trecho, e obter os parâmetros de resistência do solo que pudessem ser correlacionados para obtenção de um CBR teórico. Após as investigações 'in situ', definiu-se três pontos ao longo do trecho para coleta de amostras a serem encaminhadas para os ensaios laboratoriais.

Os solos foram classificados segundo o sistema unificado (SUCS) como argila de baixa plasticidade ("CL" ou amostras não-plásticas), embora a fração de argila tenha se apresentado em menor porcentagem na composição granulométrica do material. Em relação à classificação TRB, a amostra AM 01 foi classificada como areia siltosa A-2-4 (devido à porcentagem retida na peneira no 200 ser inferior a 35\%) e as demais, como solos siltosos do tipo A-4. Em sequência, aplicou-se a metodologia MCT para verificação do comportamento laterítico, sendo as amostras AM 01 e AM 03 classificadas como solo não-laterítico arenoso, $\mathrm{NA}^{\prime}$, e a amostra AM 02, como solo não-laterítico siltoso, NS'.

Os valores apresentados pelo ensaio de CBR apontam que a utilização do solo como camada de subleito é inviabilizada pelas padronizações normativas, ao apresentar o CBR consideravelmente baixo, problema moderado de expansão e fração de finos superior à recomendada para o uso como material de pavimentação. Os ensaios executados para avaliação da resistência (DCP e CBR) confirmaram o 
comportamento esperado do solo como material de fundação indicado pelos grupos classificatórios, onde a parcela significativa de finos influencia na baixa capacidade de suporte em solos não-lateríticos.

Os resultados e análises apresentados por este artigo permitem auxiliar estudos e projetos para avaliação dos solos como camada de fundação em pavimentos ferroviários, com base na previsão da capacidade de suporte a partir de investigações geotécnicas de campo e pelos sistemas classificatórios SUCS e TRB, MCT e demais parâmetros de caracterização tradicional.

Por fim, atrelados aos ensaios propostos, recomendam-se para trabalhos futuros a realização de ensaios dinâmicos que busquem determinar as propriedades dos materiais resilientes e permanentes (nos limites elástico e plástico, respectivamente), e o dimensionamento das camadas da infraestrutura quanto aos critérios de deformação permanente, e suas aplicações que se estendam à seleção de materiais para a pavimentação e às medidas para controle tecnológico de terraplenos ou subleitos.

\section{REFERÊNCIAS}

ALSHIBLI, K. A.; ABU-FARSAKH, M.; SEYMAN, E.. Laboratory Evaluation of the Geogauge and Light Falling Weight Deflectometer as Construction Control Tools. Journal of Materials in Civil Engineering, Miami, v.17, n.5, p.560-569, 2005. DOI: http://doi.org/10.1061/(ASCE)08991561(2005)17:5(560)

ALVARES, C. A.; STAPE, J. L.; SENTELHAS, P. C.; GONÇALVES, J. L. M.; SPAROVEK, G.. Köppen's climate classification map for Brazil. Meteorologische Zeitschrift, Stuttgart, v.22, n.6, p.711-728, 2013. DOI: http://dx.doi.org/10.1127/09412948/2013/0507

ASTM. American Society For Testing And Materials. ASTM D6951 18: Standard Test Method for Use of the Dynamic Cone Penetrometer in Shallow Pavement Applications. West Conshohocken: ASTM International, 2018.

ANGELONE, S.; TOSTICARELLI, J.; MARTINEZ, F.. El Penetrometro Dinâmico de Cono. Su Aplicación al Control y Diseño Estructural de Pavimentos. In: CONGRESSO IBEROLATINOAMERICANO DEL ASFALTO, 6. Anais. 1991.

ANTT. Associação Brasileira de Normas Técnicas. Anuário do Setor Ferroviário 2006-2018. Brasília: Ministério dos Transportes, 2019.

ABNT. Associação Brasileira de Normas Técnicas. NBR 6457: Amostras de solo: Preparação para ensaios de compactação e ensaios de caracterização. Rio de Janeiro: ABNT, 2016.

ABNT. Associação Brasileira de Normas Técnicas. NBR 9895 Versão Corrigida: Solo: Índice de suporte Califórnia (ISC): Método de ensaio. Rio de Janeiro: ABNT, 2017.

BROWN, S. F.. Soil mechanics in pavement engineering. Géotechnique, Scotland, v.46, n.3, p.383-426, 1996.

CAMPOS, P. C. O.. Avaliação do efeito da variação da umidade no comportamento mecanístico em um trecho homogêneo da Estrada de Ferro Carajás. Dissertação (Mestrado em Engenharia de Transportes) - Instituto Militar de Engenharia, Rio de Janeiro, 2019. DOI:

http://doi.org/10.13140/RG.2.2.20203.69923
CARDOSO, A. B.; TRICHÊS, G.. Utilização do Penetrômetro Dinâmico de Cone no Controle Tecnológico de Camadas Finais de Aterros Rodoviários e na Avaliação da sua Capacidade de Suporte. In: REUNIÃO ANUAL DE PAVIMENTAÇÃO, 31. Anais. São Paulo: ABPv, 1998.

CPRM. Companhia de Pesquisa de Recursos Minerais. Relatório Diagnóstico do Município de Pindaré-Mirim. Teresina: CPRM, 2011.

DARIVA, L. B.. Avaliação das propriedades físicas e mecânicas de um subleito de pavimento de via férrea do tipo heavy haul. Dissertação (Mestrado em Engenharia de Transportes) - Instituto Militar de Engenharia, Rio de Janeiro, 2016.

DELGADO, A. K. C.. Estudo do comportamento mecânico de solos tropicais característicos do distrito federal para uso na pavimentação rodoviária. Tese (Doutorado em Geotecnia) - Universidade de Brasília, Brasília, 2007.

DNER. Departamento Nacional de Estradas de Rodagem DNER-ME 080/94: Solos Análise Granulométrica por Peneiramento. Rio de Janeiro: Departamento Nacional de Estradas e Rodagem, 1994a.

DNER. Departamento Nacional de Estradas de Rodagem. DNER-ME 122/94: Solos: Determinação do limite de liquidez. Rio de Janeiro: Departamento Nacional de Estradas e Rodagem, 1994b.

DNER. Departamento Nacional de Estradas de Rodagem. DNER-ME 082/94: Solos Determinação do limite de plasticidade. Rio de Janeiro: Departamento Nacional de Estradas e Rodagem, 1994c.

DNER. Departamento Nacional de Estradas de Rodagem. DNER-ME 093/94: Solos: Determinação da densidade real. Rio de Janeiro: Departamento Nacional de Estradas e Rodagem, 1994d.

DNER. Departamento Nacional de Estradas de Rodagem. DNER-ME 256/94: Solos Compactados em Equipamento Miniatura: Determinação da Perda de Massa por Imersão. 
Rio de Janeiro: Departamento Nacional de Estradas e Rodagem, 1994e.

DNER. Departamento Nacional de Estradas de Rodagem. DNER-ME 258/94: Solos Compactados em Equipamento Miniatura - Mini-MCV. Rio de Janeiro: Departamento Nacional de Estradas e Rodagem, 1994f.

DNIT. Departamento Nacional de Infraestrutura de Transportes. DNIT ISF-207: Estudos Geotécnicos. Brasília: Departamento Nacional de Infraestrutura de Transportes, 2015.

DNIT. Departamento Nacional de Infraestrutura de Transportes. IPR 719: Manual de Pavimentação. Brasília: Departamento Nacional de Infraestrutura de Transportes, Ministério dos Transportes, 2006.

EMBRAPA. Sistema Brasileiro de Classificação de Solos. Brasília: Empresa Brasileira de Agropecuária CNPS, Serviço de Produção de Informação, 2006.

\section{FORTUNATO, E. M. C.. Renovação de Plataformas}

Ferroviárias: Estudos Relativos à Capacidade de Carga. Tese (Doutorado em Engenharia Civil) - Universidade do Porto, Portugal, 2005.

GOMES, M. S.; GUIMARÃES, A. R.; MARQUES, M. E. S.. Estudo da influência do tipo de finos no comportamento resiliente de solos tropicais para uso em pavimentos. Revista Ibero Americana de Ciências Ambientais, v.9, n.5, p.78-87, 2018. DOI: http://doi.org/10.6008/CBPC21796858.2018.005.0008

ISRAR, J.; INDRARATNA, B.. Internal Stability of Granular Filters under Static and Cyclic Loading. Journal of Geotechnical and Geoenvironmental Engineering, v.143, n.6, 2017. DOI: http://doi.org/10.1061/(ASCE)GT.1943$\underline{5606.0001661}$
MEDINA, J.; MOTTA, L. M. G.. Mecânica dos pavimentos. 3 ed. Rio de Janeiro: COPPE, 2015.

NOGAMI, J. S.; VILLIBOR, D. F.. Soil characterization of mapping units for highway purposes in a tropical area. Bulletin Of The International Association of Engineering Geology, v.19, p.196-199, 1979. DOI: http://doi.org/10.1007/BF02600475

NOGAMI, J. S.; VILLIBOR, D. F.. Uma Nova Classificação de Solos para Finalidades Rodoviárias. In: SIMPÓSIO BRASILEIRO DE SOLOS TROPICAIS EM ENGENHARIA, 1. Anais. Rio de Janeiro: ABMS, 1981.

NOGAMI, J. S.; VILLIBOR, D. F.. Pavimentação de Baixo Custo com Solos Lateríticos. São Paulo: Villibor, 1995.

NOGAMI, J. S.; VILLIBOR, D. F.. Pavimentos Econômicos: tecnologia do uso dos solos finos lateríticos. São Paulo: Arte \& Ciência, 2009.

PASTORE, E. L.; FONTES, R. M.. Caracterização e Classificação de solos. In: OLIVEIRA, A. M. S.; BRITO, S. N. A.. Geologia de Engenharia. São Paulo: ABGE, 1998.

PINTO, C. S.. Curso Básico de Mecânica dos Solos em 16 Aulas. 3 ed. São Paulo: Oficina de Textos, 2006.

SHI, P.; FAN, D.; JIA, Z.; SHI, J.. Distribution on the Deformation and Degradation of Ballast under Cyclic Loading. Journal of Geotechnical and Geoenvironmental Engineering, v.144, n.12, 2018. DOI: http://doi.org/10.1061/(ASCE)GT.1943-5606.0001961

WEBSTER, S. L.; GRAU, R. H.; WILLIAMS, R. P.. Description and Application of Dual Mass Dynamic Cone Penetrometer. Report, No. GL-92-3. Washington: Department of the Army, 1992.

A CBPC - Companhia Brasileira de Produção Científica (CNPJ: 11.221.422/0001-03) detém os direitos materiais desta publicação. Os direitos referem-se à publicação do trabalho em qualquer parte do mundo, incluindo os direitos às renovações, expansões e disseminações da contribuição, bem como outros direitos subsidiários. Todos os trabalhos publicados eletronicamente poderão posteriormente ser publicados em coletâneas impressas sob coordenação da Sustenere Publishing, da Companhia Brasileira de Produção Científica e seus parceiros autorizados. Os (as) autores (as) preservam os direitos autorais, mas não têm permissão para a publicação da contribuição em outro meio, impresso ou digital, em português ou em tradução. 